\title{
Effect of Onion Powder Supplementation on Lipid Metabolism in High Fat-cholesterol Fed SD Rats
}

\author{
Kyung-Hea Lee ${ }^{1 \dagger}$, Yangha Kim ${ }^{1}$, Eunju Park ${ }^{2}$, and Hye-Jin Hwang ${ }^{3}$ \\ ${ }^{1}$ Dept. of Food and Nutrition, Changwon National University, Changwon 641-773, Korea \\ ${ }^{2}$ Dept. of Food and Nutrition, Kyungnam University, Masan 631-701, Korea \\ ${ }^{3}$ Dept. of Food and Nutrition, Dong-Eui University, Busan 614-714, Korea
}

\begin{abstract}
This study was performed to examine the effects of onion powder supplementation on lipid metabolism in male SD rats fed a high fat and high cholesterol diet. Expenimental groups were control (C), high fat fed group (HF), high fat + onion powder intake (OP), high fat + quercetin intake (Q). The HF diet contained $1 \%$ cholesterol, $4 \%$ lard, $0.3 \%$ Na-taurocholate, and quercetin supplementation level was $0.1 \mathrm{~g} / \mathrm{kg}$ diet. The OP group showed lower body weight gains compared to the control, while there was no significant difference in food efficiency ratio efficiency. When the proportion of fecal bile acids per total lipids was calculated, there was a significant decrease in the HF group compared to the control group, while the levels of the control group was same as that of the OP group. There was no significant difference between the HF and Q groups in bile acid/total lipid in feces. The amount of total cholesterol in liver increased significantly in HF group compared to the control group, while total cholesterol decreased significantly in the OP group compared to the HF group. There was a significant decrease in GOT (glutamic oxaloacetic transaminase) activity in OP and Q groups compared to the HF group. In conclusion, feeding onion powder to hypedipidemic rates appeared to control weight gain, significantly lower the level of total cholesterol in the liver, and recover GOT activity. We also demonstrated that onion powder intake was more effective than quercetin intake.
\end{abstract}

Key words: onion, quercetin, lipid metabolism, hyperlipidemic

\section{INTRODUCTION}

Cardiovascular diseases are the leading cause of death in Korea, as well as many of the Western countries. Apart from smoking, hypertension and diabetes, high LDL (low density lipoprotein) cholesterol levels are the primary cause of atherosclerosis. It has been shown that the onset and death rates for cardiovascular diseases can be reduced if the risk factor for coronary artery disease is controlled properly $(1,2)$.

Onion (Allium cepa L.) is one of the major sources of dietary flavonoids in many countries $(3,4)$. Many studies have found that quercetin is the most active of the flavonoids contained in many plants and exhibits strong free radical scavenging activity, and that its interaction with a variety of human proteins leads to a high level of biological activity which enhances dietary effects. The anti-arteriosclerotic properties of quercetin include a wide range of effects, including antioxidant, anti-inflammatory, anti-tumour and anti-clotting activity (5).

Recent epidemiological studies have reported that dietary fiber plays important physiological and metabolic roles in preventing chronic and degenerative diseases (6). Fruits and vegetables contain a wide variety of antioxidants including dietary fiber, antioxidant vitamins, flavonoid pigments, phenolic groups and aromatic amines, and there have been many studies on their physiological activity (7). In particular, onions are widely used in almost every type of food worldwide. World onion production has increased by at least $25 \%$ over the past 10 years with current production being around 44 million tons making it the second most important horticultural crop after tomatoes (5).

Onion has many powerful flavonoid pigment-containing compounds, such as quercetin and rutin, that are potent antioxidants. Also, onions contain allyl propyl disulfide, diallyl disulfide and others that help lower the level of lipids (8). Many studies have suggested that onions contain heavy metal detoxification, antibiotic, blood sugar reduction, cardiovascular disease prevention, xanthine oxidase inhibition, antioxidant, and anticancer components (9-11).

This study was performed to examine the effects of onion powder and quercetin supplementation on blood

${ }^{\dagger}$ Corresponding author. E-mail: khl@changwon.ac.kr

Phone: +82-55-213-3514, Fax: +82-55-281-7480 
lipid profiles and bile acid in the liver in male SD rats fed a high fat and cholesterol diet.

\section{MATERIALS AND METHODS}

\section{Diet and animals}

Experimental groups were labeled as control (C), high fat fed group (HF), high fat+onion powder intake (OP), high fat+quercetin intake (Q) (Table 1). For this study, onion samples were collected from Changnyeong area and prepared to produce a fine powder that could pass through a \#40 mesh.

Quercetin was isolated form the freeze-dried onion powder by using a solution containing $80 \%$ methanol. The dehydrated quercetin was analyzed using HPLC and showed that $100 \mathrm{~g}$ of onion powder contain $277.28 \mathrm{mg}$ of quercetin. The onion powder composition was $50 \mathrm{~g} / \mathrm{kg}$ diet of diet and the standard quercetin level was $0.01 \%$ $(0.1 \mathrm{~g}$ of quercetin per $1 \mathrm{~kg}$ diet $)$.

Male rats were bred in the Animal Unit under controlled conditions $\left(22 \sim 24^{\circ} \mathrm{C}\right.$, RH $\left.50 \sim 60 \%\right)$, and provided food and water ad libitum. The weight of each animal was $100 \mathrm{~g}$ (6-weeks old) at the beginning of the study and these animals were fed the specified diet for the 8-week study period. Daily feed intake and weekly body weight gain were routinely recorded throughout the experimental period using Computingscale (CAS Co., Korea).

Table 1. Composition of experimental diets $(\mathrm{g} / \mathrm{kg})$

\begin{tabular}{lcccc}
\hline \multirow{2}{*}{ Ingredient } & \multicolumn{4}{c}{ Group $^{1)}$} \\
\cline { 2 - 5 } & $\mathrm{C}$ & $\mathrm{HF}$ & $\mathrm{OP}$ & $\mathrm{Q}$ \\
\hline Casein & 150 & 150 & 150 & 150 \\
Corn starch & 576 & 548 & 498 & 548 \\
Sucrose & 100 & 100 & 100 & 100 \\
Corn oil & 60 & 60 & 60 & 60 \\
Soybean oil & 40 & 40 & 40 & 40 \\
Lard & - & 40 & 40 & 40 \\
Cholesterol & - & 10 & 10 & 10 \\
Cellulose & 25 & - & - & - \\
Mineral mix. ${ }^{2)}$ & 35 & 35 & 35 & 35 \\
Vitamin mix. & 10 & 10 & 10 & 10 \\
Choline chloride & 2 & 2 & 2 & 2 \\
DL-methionine & 1.8 & 1.8 & 1.8 & 1.8 \\
Na-taurocholate & - & 3 & 3 & 3 \\
Onion powder (OP) & - & - & 50 & - \\
Quercetin & - & & & 0.1 \\
BHT $^{4}$ & 0.01 & 0.01 & 0.01 & 0.01 \\
\hline Total & 999.81 & 999.81 & 999.81 & 999.91 \\
\hline
\end{tabular}

${ }^{1)} \mathrm{C}$ : control, HF: high fat fed group, OP: high fat + onion powder intake, Q: high fat + quercetin intake.

2) AIN-76 mineral mix.

3) AIN-76 vitamin mix.

${ }^{4)}$ Dibutylated hydroxytoluene

\section{Collection of blood \& fecal samples and rat organ extraction}

Five days before the end of the 8-week feeding period, the fecal samples of the rat were collected every day, and were freeze-dried after measuring their weight. The feed container was removed and the rats were not fed 12 hours prior to sacrifice. After they were anesthetized with diethyl ether, blood samples were collected from the abdominal aorta, and the rat's internal organs such as the colon, liver, kidney, heart and spleen were extracted and weighed. The colon and liver were rapidly frozen with liquid nitrogen and stored in the freezer at $-80^{\circ} \mathrm{C}$. Some blood samples were put in a lithium-heparinic polystyrene tube, the alkaline comet assay on the blood sample was immediately performed within 2 hours and the remaining blood sample was centrifuged at 3000 rpm for 15 minutes. Then, the separated plasma was stored in a freezer at $-80^{\circ} \mathrm{C}$ before measuring the amount of total lipids.

\section{Measurement of lipid profile in plasma, liver and feces}

Total cholesterol in blood plasma was measured using an Allain kit (Bioclinical system, Korea) (12). The HDL (high density lipoprotein) concentration was measured by the method same as total cholesterol after isolation of dextran sulfate- $\mathrm{MnCl}_{2}$ precipitation (13). Triglyceride concentration was measured using the BCS kit (Bioclinical system, Korea) based on the lipase-glycerolphosphate oxidase method (14). LDL (low density lipoprotein)-cholesterol was calculated using the method of Friedewald [Total cholesterol-(HDL cholesterol-triglyceride/5)], and LDL-cholesterol levels were calculated using the method of Friedwald. The atherogenetic index was calculated as follows: Atherosclerotic index $=$ (total cholesterol-HDL- cholesterol/HDL- cholesterol).

The amount of total lipids in the liver and fecal samples was determined using the method of Folch et al. (15) and the level of bile acids in the fecal sample was measured using a bile acid kit using the method of Tokunage et al. (16) after the extraction of bile acids from the feces. Blood GOT (glutamic oxaloacetic transaminase) and GPT (glutamic pyruvic transaminase) activities were measured using an automatic blood analyzer using a diagnostic test kit and reagent (need to state name of kit and its manufacturer) to evaluate liver functions.

\section{Statistical analysis}

Statistical analysis was performed using the SPSS program. The results were presented as mean \pm SEM and the differences among experimental groups were analyzed using a one-way analysis of variance (ANOVA) with Duncan's multiple range test at $\mathrm{p}<0.05$. 
Table 2. Food intake, weight gains and food efficiency ratio of the experimental group

\begin{tabular}{lcrrr}
\hline \multirow{2}{*}{ Variables } & \multicolumn{3}{c}{ Group $^{1)}$} \\
\cline { 2 - 5 } & \multicolumn{1}{c}{$\mathrm{C}$} & HF & OP & Q \\
\hline Food intake (g/day) & $15.6 \pm 1.9^{\text {ab2) }}$ & $15.7 \pm 1.4^{\mathrm{ab}}$ & $14.7 \pm 2.1^{\mathrm{a}}$ & $16.6 \pm 2.3^{\mathrm{b}}$ \\
Body weight gain (g/8 wk) & $216.5 \pm 18.6^{\mathrm{a}}$ & $231.3 \pm 23.8^{\mathrm{ab}}$ & $208.1 \pm 23.0^{\mathrm{a}}$ & $251.8 \pm 34.0^{\mathrm{b}}$ \\
FER $^{3)}$ & $0.29 \pm 0.02^{\text {ns4) }}$ & $0.31 \pm 0.03$ & $0.30 \pm 0.03$ & $0.32 \pm 0.04$ \\
\hline
\end{tabular}

${ }^{1}$ Refer to Table 1 .

${ }^{2)}$ Values with the different letter within the same row are significantly different by Duncan's multiple range at $\mathrm{p}<0.05$. Values are the mean \pm SEM of 8 rats for 8 weeks in each group.

${ }^{3)}$ Food efficiency ratio.

${ }^{4)}$ Not significant.

\section{RESULTS AND DISCUSSION}

\section{Food intakes, weight changes and organ weight changes}

While there was no significant difference in food intake among experimental groups, Q group showed significantly greater intakes of food and higher body weight gains compared to OP group. There was no significant difference in food efficiency ratio(Table 2).

Onions are very rich in fiber (19\% in dry weight), and insoluble fiber which helps not only clear carcinogenic or potentially carcinogenic substances (including bile acid) more quickly, but also make these carcinogenic substances be more watery in the colon (5). It is also known that the soluble fiber intake reduces the risk of cardiovascular diseases by lowering cholesterol levels in the blood (17). While there is a significant difference in functions between the two fibers, onions are so rich in both soluble and non-soluble fiber that they can be very effective for weight loss, as well as for prevention against cardiovascular diseases $(5,18)$.

The weights of extracted organs are shown in Table 3. We found a significant increase in the liver weight of the HF group compared to the control group. There was no significant difference in the heart and kidney weights between all experimental groups, However, there was a significant increase in the spleen weight of the HF group compared to the control group.
Table 3. Percent of organ weight of the experimental group

$(\%)$

\begin{tabular}{lllll}
\hline \multirow{2}{*}{ Variables } & \multicolumn{4}{c}{ Group $^{1)}$} \\
\cline { 2 - 5 } & \multicolumn{1}{c}{$\mathrm{C}$} & \multicolumn{1}{c}{ HF } & \multicolumn{1}{c}{ OP } & \multicolumn{1}{c}{$\mathrm{Q}$} \\
\hline Liver & $2.8 \pm 0.1^{\mathrm{a} 2)}$ & $5.0 \pm 0.1^{\mathrm{b}}$ & $5.3 \pm 0.4^{\mathrm{c}}$ & $5.3 \pm 0.2^{\mathrm{c}}$ \\
Heart & $0.4 \pm 0.0^{\mathrm{ns} 3)}$ & $0.4 \pm 0.0$ & $0.4 \pm 0.0$ & $0.3 \pm 0.0$ \\
Spleen & $0.2 \pm 0.0^{\mathrm{a}}$ & $0.3 \pm 0.1^{\mathrm{b}}$ & $0.3 \pm 0.0^{\mathrm{b}}$ & $0.3 \pm 0.0^{\mathrm{b}}$ \\
Kidney & $0.7 \pm 0.0^{\mathrm{ns}}$ & $0.6 \pm 0.0$ & $0.6 \pm 0.1$ & $0.6 \pm 0.0$ \\
\hline
\end{tabular}

${ }^{1)}$ Refer to Table 1 .

${ }^{2)}$ Values with the different letter within the same row are significantly different by Duncan's multiple range at $\mathrm{p}<0.05$. Values are the mean \pm SEM of 8 rats group.

${ }^{3)}$ Not significant.

\section{Fecal lipid profiles}

The fecal weight and lipid profile are shown in Table 4. There was a significant decrease in the fecal weight of the HF group compared to the control group, while no significant difference was found between the OP group and the control group. There was a significant decrease in the fecal weight of the Q group compared with the control and OP groups The total lipid content in feces were significantly higher in the HF group compared to other groups, and the Q group was significant higher than in control and OP group. In general we found that onion powder intake has no significant effect on the amount of total lipids in feces, except for the significant increase in fecal triglycerides. On the other hand, the addition of onion powder and quercetin could decrease

Table 4. Bile acid and lipid profiles in the feces of the experimental group

\begin{tabular}{lcccc}
\hline \multirow{2}{*}{ Variables } & \multicolumn{3}{c}{ Groups $^{1)}$} \\
\cline { 2 - 5 } & $\mathrm{C}$ & HF & OP & Q \\
\hline Fecal weight (g wet wt/d) & $0.9 \pm 0.1^{\mathrm{c} 2)}$ & $0.7 \pm 0.0^{\mathrm{b}}$ & $0.8 \pm 0.1^{\mathrm{c}}$ & $0.6 \pm 0.1^{\mathrm{a}}$ \\
Total lipid (mg/g dry wt) & $27.4 \pm 4.4^{\mathrm{a}}$ & $110.9 \pm 19.7^{\mathrm{d}}$ & $68.4 \pm 8.5^{\mathrm{b}}$ & $94.0 \pm 14.2^{\mathrm{c}}$ \\
Total cholesterol (mg/g dry wt) & $4.2 \pm 0.5^{\mathrm{a}}$ & $53.5 \pm 6.8^{\mathrm{b}}$ & $47.5 \pm 3.9^{\mathrm{b}}$ & $49.7 \pm 5.9^{\mathrm{b}}$ \\
Triglycerides (mg/g dry wt) & $0.6 \pm 0.0^{\mathrm{a}}$ & $1.2 \pm 0.1^{\mathrm{a}}$ & $1.8 \pm 0.1^{\mathrm{b}}$ & $2.0 \pm 0.1^{\mathrm{b}}$ \\
Bile acid (mg/g dry wt) & $12.2 \pm 2.9^{\mathrm{a}}$ & $34.0 \pm 3.6^{\mathrm{b}}$ & $30.6 \pm 5.1^{\mathrm{b}}$ & $30.8 \pm 5.2^{\mathrm{b}}$ \\
Bile acid/Total lipid (\%, wt/wt\%) & $44.5 \pm 8.6^{\mathrm{b}}$ & $30.6 \pm 12.3^{\mathrm{a}}$ & $44.4 \pm 10.0^{\mathrm{b}}$ & $32.8 \pm 10.9^{\mathrm{ab}}$ \\
\hline
\end{tabular}

\footnotetext{
${ }^{1)}$ Refer to Table 1 .

${ }^{2)}$ Values with the different letter within the same row are significantly different by Duncan's multiple range at $\mathrm{p}<0.05$. Values are the mean \pm SEM of 8 rats.
} 
the amount of total lipids in feces compared to that of HF group, while fecal triglyceride levels was significant increase in $\mathrm{Q}$ group compared to the HF group, being similar to the OP group

When fecal excretion of total sterols was analyzed (19), neutral sterol was shown to account for $55 \%$ of the total sterols in feces, and bile acid accounted for $45 \%$. The increases in the excretion of bile acids and sterols might be one of the mechanisms for lowering cholesterol (20). The results of this study of onion powder supplementation showed that onion or quercetin intake had little or no effect on the fecal bile acid contents in the HF group, although the fecal bile acid contents of the HF group and the control group were significantly different. When the proportion of fecal bile acids in total lipids was calculated, we found that there was a significant decrease in the HF group compared to the control group, that the proportion of the control group was same as that of the OP and Q groups.

\section{Lipid profiles in the liver and plasma}

The lipid profiles in liver are shown in Table 5. The HF group showed a significant increase in the amount of total lipids in the liver compared to the control group. When the onion powder was added to their diets, there was no significant difference in the amount of total lipids in liver. There were no significant differences in triglyceride concentration among the groups. The amount of total cholesterol significantly increased in the HF group compared to the control group, while it decreased significantly in the OP group.

The effects of onion powder supplementation on lipid profiles in plasma are shown in Table 6. The plasma triglyceride levels significantly decreased in the OP and HF groups compared to the control group. However, there was no significant difference in the effects of onion powder intake between the HF group and other diet groups. In addition, no significant differences were found in both the plasma HDL-cholesterol/total cholesterol proportion and atherosclerotic index (AI) among $\mathrm{HF}$, OP and Q group.

It has been known that Na-taurocholate causes cholesterol accumulation in the liver (21). The group fed high fat-cholesterol diets with $0.3 \%$ Na-taurocholate showed significantly larger increases in the amount of total lipids in the liver compared to the control group. When onion powder was added, there was no significant change in the amount of total lipids. No significant difference was found in the triglyceride among groups. The total cholesterol concentration in liver increased significantly in the $\mathrm{H}$ group compared to the control group, while it decreased significantly in the OP group as compared to $\mathrm{H}$ group. The total cholesterol concentration of the quercetin group decreased slightly but was not significantly different from the $\mathrm{H}$ group. Quercetin in onions occurs

Table 5. Lipid profiles in the liver of the experimental group

\begin{tabular}{|c|c|c|c|c|}
\hline \multirow{2}{*}{ Variables } & \multicolumn{4}{|c|}{ Group $^{1)}$} \\
\hline & $\mathrm{C}$ & $\mathrm{HF}$ & $\mathrm{OP}$ & $\mathrm{Q}$ \\
\hline Total lipids & $31.4 \pm 10.1^{\mathrm{a} 2)}$ & $229.8 \pm 29.4^{b}$ & $200.1 \pm 24.1^{b}$ & $230.3 \pm 37.5^{b}$ \\
\hline Triglyceride & $17.3 \pm 2.2^{\mathrm{ns} 3)}$ & $18.4 \pm 9.9$ & $16.3 \pm 2.6$ & $21.2 \pm 2.0$ \\
\hline Total cholesterol & $69.9 \pm 12.0^{\mathrm{a}}$ & $90.3 \pm 3.9^{c}$ & $80.9 \pm 7.0^{\mathrm{b}}$ & $82.4 \pm 5.3^{b c}$ \\
\hline
\end{tabular}

${ }^{1)}$ Refer to Table 1.

${ }^{2)}$ Values with the different letter within the same row are significantly different by Duncan's multiple range at $\mathrm{p}<0.05$. Values are the mean \pm SEM of 8 rats.

${ }^{3)}$ Not significant.

Table 6. Lipid profiles in plasma of the experimental group

$(\mathrm{mg} / \mathrm{dL})$

\begin{tabular}{lcrrr}
\hline \multirow{2}{*}{ Variables } & \multicolumn{3}{c}{ Group $^{1)}$} \\
\cline { 2 - 5 } & \multicolumn{1}{c}{$\mathrm{C}$} & HF & \multicolumn{1}{c}{ OP } & Q \\
\hline Triglyceride & $65.1 \pm 2.6^{\mathrm{b} 2)}$ & $47.1 \pm 3.1^{\mathrm{a}}$ & $39.75 \pm 1.1^{\mathrm{a}}$ & $80.9 \pm 4.6^{\mathrm{c}}$ \\
Total cholesterol & $49.0 \pm 3.8^{\mathrm{a}}$ & $99.3 \pm 7.6^{\mathrm{b}}$ & $101.88 \pm 6.2^{\mathrm{b}}$ & $111.3 \pm 3.1^{\mathrm{b}}$ \\
HDL-Cholesterol & $31.6 \pm 2.2^{\mathrm{b}}$ & $17.8 \pm 1.7^{\mathrm{a}}$ & $16.81 \pm 1.3^{\mathrm{a}}$ & $15.9 \pm 0.8^{\mathrm{a}}$ \\
LDL-Cholesterol & $4.4 \pm 3.4^{\mathrm{a}}$ & $72.1 \pm 8.6^{\mathrm{b}}$ & $77.11 \pm 6.1^{\mathrm{b}}$ & $79.1 \pm 3.4^{\mathrm{b}}$ \\
HDL-C/TC & $0.7 \pm 0.2^{\mathrm{a}}$ & $0.2 \pm 0.1^{\mathrm{b}}$ & $0.2 \pm 0.0^{\mathrm{b}}$ & $0.1 \pm 0.0^{\mathrm{b}}$ \\
AI $^{4)}$ & $0.59 \pm 0.33^{\mathrm{a}}$ & $5.11 \pm 2.4^{\mathrm{b}}$ & $5.33 \pm 2.0^{\mathrm{b}}$ & $6.06 \pm 0.8^{\mathrm{b}}$ \\
\hline
\end{tabular}

\footnotetext{
${ }^{1)}$ Refer to Table 1.

${ }^{2)}$ Values with the different letter within the same row are significantly different by Duncan's multiple range at $\mathrm{p}<0.05$. Values are the mean $\pm \mathrm{SEM}$ of 8 rats for 8 weeks in each group.

${ }^{3)} \mathrm{HDL}-\mathrm{C} / \mathrm{TC}=\mathrm{HDL}-$ cholesterol/Total cholesterol

${ }^{4)}$ AI (Atherosclerotic index $)=($ Total cholesterol-HDL-cholesterol)/HDL-cholesterol
} 
Table 7. GOT and GPT activities in plasma of the experimental group

\begin{tabular}{ccrrr}
\hline \multirow{2}{*}{ Variables } & \multicolumn{4}{c}{ Groups $^{1)}$} \\
\cline { 2 - 5 } & $\mathrm{C}$ & $\mathrm{HF}$ & $\mathrm{OP}$ & $\mathrm{Q}$ \\
\hline GOT $^{2)}$ & $75.8 \pm 8.9^{\mathrm{a} 4)}$ & $162.6 \pm 45.0^{\mathrm{c}}$ & $121.0 \pm 29.0^{\mathrm{b}}$ & $142.3 \pm 35.9 \mathrm{~b}$ \\
GPT $^{3)}$ & $30.5 \pm 5.8^{\mathrm{a}}$ & $72.8 \pm 28.0^{\mathrm{b}}$ & $75.6 \pm 21.4^{\mathrm{b}}$ & $61.3 \pm 22.8^{\mathrm{b}}$ \\
\hline
\end{tabular}

${ }^{1)}$ Refer to Table 1.

${ }^{2)}$ GOT: Glutamic oxaloacetic transaminase.

${ }^{3)}$ GPT: Glutamic pyruvic transaminase.

${ }^{4)}$ Values with the different letter within the same row are significantly different by Duncan's multiple range at $\mathrm{p}<0.05$. Values are the mean \pm SEM for 8 rats.

mainly as a mixture of the $4^{\prime}$-monoglucoside and 3,4'-diglucoside and a number of studies indicate that these have a much greater bioavailability than quercetin from other food sources containing different sugar moieties $(22,23)$.

When blood lipids were examined in this study, we found a significant decrease in plasma triglyceride levels in the OP and HF groups after the intake of $1 \%$ cholesterol, $4 \%$ lard and $0.3 \%$ Na-taurocholate. We also found that there was no significant difference in the effects of onion intake between the HF group and other experimental groups. In addition, no difference was found in both the HDL-cholesterol/total cholesterol proportion and atherosclerotic index (AI).

Some epidemiological studies $(24,25)$ have reported that high intake of dietary flavonoids is associated with the reduction in the risk of cardiovascular diseases, and the studies carried out with two animal models reported that quercetin demonstrates anti-arteriosclerotic activity and blood lipid reduction activity. Ajay et al. (26) indicated that quercetin acutely improved vascular responsiveness in blood vessels from diabetic rats, and that these effects were mediated by enhanced endothelial nitric oxide bioavailability. It has been known that $7 \alpha$ -hydroxylase activity depending on cytochrome P450 is closely associated with cholesterol metabolism. Juzwiak et al. (27) reported that quercetin helps increase the amount of cytochrome P450 in the liver. It is possible, therefore, that adding the quercetin compound helps change cholesterol to bile acid by activating the microsomal $7 \alpha$-hydroxylation in the liver.

Yugarani et al. (28) reported, however, when rats with dietary arteriosclerosis were fed quercetin for 10 weeks, the level of HDL-cholesterol increased but the level of LDL-cholesterol decreased, without any change in triglyceride and total cholesterol. Because the CETP (cholesteryl ester transfer protein activity) in the liver varies according to animal species, there is also a difference in the effects of flavonoids on plasma concentration of HDL and LDL. This experiment was performed with rats during an 8-week period and it seems, therefore, that the study period was not long enough to demonstrate the blood lipid level lowering activity of quercetin. Juzwiak et al. (27) reported that when rabbits with hyperlipidemia and arteriosclerosis were fed a high fat-cholesterol diet and evaluated after the addition of quercetin to their diet, no significant effect was found during the first 4-week period, but quercetin was effective in reducing triglycerides and cholesterol level elevated by high fat diet, after 12 weeks of the experiment.

\section{GOT and GPT activities in plasma}

The GOT and GPT activities in plasma are shown in Table 7. Increased activities of GOT and GPT have been shown in the liver injury (29). The GOT and GPT activities were significantly higher in the HF group compared to the control group, while GOT activity significantly decreased in the OP group and Q group compared to HF group, without any effect on GPT.

Based our findings, onion powder fed to hyperlipidemic rats controlled weight gain, significantly lowered the level of total cholesterol in the liver, and recovered GOT activity. Onions rich in polyphenol and fiber were more effective in triggering these effects compared to purified quercetin.

\section{ACKNOWLEDGEMENT}

This work has been supported by Changnyeong Onion and Soy Products Industry Promotion Program of the Korean Ministry of Commerce, Industry, and Energy.

\section{REFERENCES}

1. Nam KH, Baik HW, Choi TY, Yoon SG, Park SW, Joung HJ. 2007. Effects of ethanol of onion on the lipid profiles in patients with hypercholesterolemia. Korean J Nutr 40: 242-248.

2. Lee YC, Synn HA, Lee KY, Park YH, Lee CS. 1992. A study on concentrations of serum lipids and food lipids and food \& daily habit of study of healthy Korean adults. Korean J Lipidology 2: 41-51.

3. Hertog MG, Hollman PCH. 1996. Potential health effects of dietary flavonol quercetin. Eur J Clin Nutr 50: 63-71.

4. Knekt P, Jarvinen R, Reunanen A, Maatela J. 1996. 
Flavonoid intake and coronary mortality in Finland: a cohort study. BMJ 312: 478-481.

5. Griffiths G, Trueman L, Crowther T, Thomas B, Smith B. 2002. Onions--a global benefit to health. Phytother Res 16: 603-615.

6. Martin-Carron N, Saura-Calixto F, Goni I, ALarrauri J, Garcia-Alonso A, Saura-Calixto F. 2000. Reduction in serum total LDL-cholesterol concentration by a dietary fiber and polyphenol-rich grape product in hypercholesterolemic rats. Nutr Res 9: 1183-1188.

7. Lampe JW. 1999. Health effects of vegetables and fruit: assessing mechanism of action in human experimental studies. Am J Clin Nutr 70: 475S-490S.

8. Slimestad R, Fossen T, Vagen IM. 2007. Onions: a source of unique dietary flavonoids. J Agric Food Chem 55: 10067-10080.

9. Lee MK, Chung YH, Nam HK. 1999. Studies on the heavy metals elimination and antioxidation of the onion ethanolic extract. J Korean Oil Chemists' Soc 16: 143-146.

10. Orvis KS, Goldman IL, Barak P. 2001. Excess sulfate supply and onion-induced human antiplatelet activity. J Plant Nutr Soil Sci 164: 457-462.

11. Hertog MG, Feskens EJ, Hollman PC, Katan MB, Kromhout D. 1993. Dietary antioxidant flavonoids and risk of coronary heart disease. Lancet 342: 1007-1011.

12. Allain CC, Poon LS, Chan CS, Richmond W, Fu PC. 1974. Enzymatic determination of total serum cholesterol. Clin Chem 20: 470-475.

13. Warnick GR, Mayfield C, Benderson J, Chen JS, Albers JJ. 1982. HDL cholesterol quantitation by phosphotungstate-Mg2+ and by dextran sulfate-Mn2+-polyethylene glycol precipitation, both with enzymic cholesterol assay compared with the lipid research method. Am J Clin Patho 78: 718-723.

14. McGowan MW, Artiss JD, Strandbergh DR, Zak BA. 1983. Peroxidase-coupled method for the colorimetric determination of serum triglycerides. Clin Chem 29: 538542.

15. Folch J, Lees M, Stanley S. 1957. A simple method for isolation and purification of total lipids from animal tissues. J Biol Chem 226: 497-509.

16. Tokunaga T, Oku T, Hosoya N. 1986. Influence of chronic intake of new sweetener fructooligosaccharide (neosugar) on growth and gastrointestinal function of the rat. $J$ Nutr Sci Vitaminol 32: 111-121.

17. Lupton JR, Tumer ND. 2003. Dietary fiber and coronary disease: does the evidence support an association? Curr
Atheroscler Rep 5: 500-505.

18. Kendler BS. 1987. Garlic (Allium sativum) and onion (Allium cepa): a review of their relationship to cardiovascular disease. Prev Med 16: 670-685.

19. James LG, Sareen SG, Sara M. 1995. Advanced nutrition and human metabolism. 2nd ed. West Publication Co., Minneapolis/St. Paul. p 135-146.

20. Kumari K, Augusti KT. 2007. Lipid lowering effect of S-methyl cysteine sulfoxide from Allium cepa Linn in high cholesterol diet fed rats. J Ethnopharmacol 109: 367-37.

21. Gartung C, Schuele S, Schlosser SF, Boyer JL. 1997. Expression of the rat liver $\mathrm{Na}+$ /taurocholate cotransporter is regulated in vivo by retention of biliary constituents but not their depletion. Hepatology 25: 284-290.

22. Arts ICW, Sesinl ALA, Faassen-Oeters M, Hollman PCH. 2004. The type of sugar moiety is a major determinant of the small intestinal uptake and subsequent biliary excretion of dietary quercetin glycosides. British J Nutr 91: 841-847.

23. Hollman PDH, van Trijp JMP, Buysman MNCP, van der Gaag MS, Mengelers MJB, de Vries JHM, Katan MB. 1997. Relative bioavailability of the antioxidant quercetin from various foods in man. FEBS Letters 418: 152-156.

24. Hertog MG, Feskens EJ, Hollman PC, Katan MB, Kromhout D. 1993. Dietary antioxidant flavonoids and risk of coronary heart disease: the Zutphan Eldary Study. Lancet 342: 1007-1011.

25. Knekt P, Jarvinen R, Reunanen A, Maatela J. 1995. Flavonoid intake and long-term risk of coronary heart disease and cancer in the Seven Countries Study. Arch Intern Med 155: 381-386.

26. Ajay M, Achike FI, Mustafa AM, Mustafa MR. 2006. Effect of quercetin on altered vascular reactivity in aortas isolated from streptozotocin-induced diabetic rats. Diabete Res Clin Pract 73: 1-7.

27. Juzwiak S, Wojcicki J, Mokrzycki K, Marchlewicz M, Boatecka M, Wenda- Rozewicka L, Gawronska-Szklarz B, Drozdzik M. 2005. Effect of quercetin on experimental hyperlipidemia and atherosclerosis in rabbits. Pharmacological Reports 57: 604-609.

28. Yugarani T, Tan BK, Teh M, Das NP. 1992. Effects of polyphenolic natural products on the lipid profile of rats fed high-fat diet. Lipids 27: 181-186.

29. Bergmeyer HU. 1995. Methods of enzymatic analysis. Verlag Chemie, Academic press, Weinheim. Vol 1, p 2028.

(Received March 31, 2008; Accepted May 19, 2008) 